\title{
High-speed optical interconnects with 850nm VCSELS and advanced modulation formats
}

Krzysztof Szczerba

Tamás Lengyel

Zhongxia $\mathrm{He}$

Jingjing Chen

Peter A. Andrekson

Magnus Karlsson

Herbert Zirath

Anders Larsson 
Invited Paper

\title{
High speed optical interconnects with $850 \mathrm{~nm}$ VCSELs and advanced modulation formats
}

\author{
Krzysztof Szczerba ${ }^{\mathrm{a}}$, Tamás Lengyel ${ }^{\mathrm{b}}$, Zhongxia $\mathrm{He}^{\mathrm{c}}$, Jingjing $\mathrm{Chen}^{\mathrm{c}}$, Peter A. Andrekson ${ }^{\mathrm{b}}$, \\ Magnus Karlsson ${ }^{\mathrm{b}}$, Herbert Zirath ${ }^{\mathrm{c}}$, and Anders Larsson ${ }^{\mathrm{b}}$ \\ ainisar Corporation, 1389 Moffet Park Dr., Sunnyvale, CA 94089, USA \\ ${ }^{\mathrm{b}}$ Photonics Laboratory, Department of Microtechnology and Nanoscience, Chalmers University \\ of Technology, SE-41296 Göteborg, Sweden \\ ${ }^{\mathrm{c}}$ Microwave Electronics Laboratory, Department of Microtechnology and Nanoscience, \\ Chalmers University of Technology, SE-41296 Göteborg, Sweden
}

\begin{abstract}
We present our recent work on high-speed optical interconnects with advanced modulation formats and directly modulated $850 \mathrm{~nm}$ VCSELs. Data transmission at nearly 100 Gbps was achieved with 4-PAM. Forward error correction, equalization and preemphasis are also explored. The system aspects of the advanced modulation formats and their impact on the VCSEL requirements are discussed. Requirements on the optical output power, frequency response and the relative intensity noise are discussed. Finally, co-optimization of the VCSELs and VCSEL driver amplifiers in CMOS and InP technologies is discussed.
\end{abstract}

Keywords: vertical-cavity surface-emitting laser, optical interconnect, multilevel modulation, PAM

\section{INTRODUCTION}

Short range optical links, such as in datacenters and supercomputers commonly use directly modulated vertical cavity surface emitting lasers (VCSELs), operating at the wavelength of $850 \mathrm{~nm}$. The typical transmission medium is multimode fiber (MMF). While it has a limited bandwidth distance product due to modal and chromatic dispersion, the large core diameter results in a large alignment tolerance and consequently helps keep the transceiver cost low. Data in such a link is transmitted using intensity modulation and direct detection (IM/DD), which means that simple photodiodes can be used in the receiver.

VCSELs offer several unique advantages, which made them popular in datacom applications. They are energy efficient, energy dissipation of $73 \mathrm{fJ} /$ bit at $40 \mathrm{Gbps}$ and $95 \mathrm{fJ} /$ bit at $50 \mathrm{Gbps}$ reported in 1 . Even lower energy dissipation of $56 \mathrm{fJ} /$ bit at $25 \mathrm{Gbps}$ was reported in 2. The VCSELs can also be directly modulated at very high data rates, demonstrated at as high as 57 Gbps using on-off keying (OOK) without equalization ${ }^{3}$ and 71 Gbps using OOK with transmitter and reciever equalization. ${ }^{4}$ The need for short-reach optical interconnects operating at 100 Gbps and above has resulted in significant research and development efforts. ${ }^{5}$ At the moment, it appears that the most practical way of achieving $100 \mathrm{Gbps}$ data rate in a single link is to use multilevel modulation. There are many possible multi-level modulation formats which can be used in IM/DD links, which can be roughly categorized into two classes - subcarrier and pulse amplitude modulation. Subcarrier modulation techniques use one or more, possibly orthogonal subcarriers, each of which can be modulated. The advantage of multiple subcarrier formats is that adaptable bit loading can be used, to maximally exploit the channel frequency response. ${ }^{6,7}$ The disadvantages are required signal processing complexity and high optical power requirements. Therefore, pulse amplitude modulation has attracted a significant attention and is currently being standardized for the next generation of Ethernet. ${ }^{8}$ A combination of 4-PAM, duobinary signaling and forward error correction (FEC) has allowed a data rate of $112 \mathrm{Gbps}$ (minus the FEC overhead) with an $850 \mathrm{~nm}$ VCSEL,${ }^{9}$ later improved to 150 Gbps. ${ }^{10}$ The highest reported data rate with 4-PAM without FEC and without equalization using an $850 \mathrm{~nm}$ VCSEL is 60 Gbps. ${ }^{11}$ With receiver equalization and FEC, 70 Gbps was achieved with 4-PAM, ${ }^{12}$ and

Further author information: (Send correspondence to K. Szczerba)

E-mail: krzysztof.szczerba@finisar.com

Vertical-Cavity Surface-Emitting Lasers XXI, edited by Kent D. Choquette,

Chun Lei, Proc. of SPIE Vol. 10122, 101220G · ( 2017 SPIE

CCC code: $0277-786 \mathrm{X} / 17 / \$ 18 \cdot$ doi: $10.1117 / 12.2256992$

Proc. of SPIE Vol. 10122 101220G-1 
later improved to nearly 100 Gbps. ${ }^{13}$ In 1471.8 Gbps 4-PAM with transmitter pre-emphasis only and low overhead FEC was reported. Maximul likelihood sequence estimation has allowed a data rate of 112 Gbps for 4-PAM in a link with bandwidth limited by a $22 \mathrm{GHz}$ photoreceiver. ${ }^{15}$ High data rates with 4-PAM were reported in $1550 \mathrm{~nm}$ systems, e.g. in 16 where 112 Gbps 4-PAM transmission was demonstrated using a $30 \mathrm{GHz}$ Mach-Zehnder modulator (MZM) driven directly by a custom 4-PAM circuit. Further, 214 Gbps 4-PAM was shown using an electro-absorption modulator with more than $50 \mathrm{GHz}$ modulation bandwidth integrated with a distributed feedback laser. ${ }^{17}$ In both cases use of FEC was necessary, and in the latter case also an off-line equalizer with up to 21 taps.

Multilevel PAM was used also to improve the transmission reach in the MMF. 4-PAM transmission over up to $200 \mathrm{~m}$ of OM4+ MMF at 50 Gbps data rate was demonstrated using an $850 \mathrm{~nm}$ VCSEL. ${ }^{18,19}$ In 20,104 Gbps transmission over $50 \mathrm{~m}$ was demonstrated using two wavelengths, $850 \mathrm{~nm}$ and $880 \mathrm{~nm}$, carrying a $52 \mathrm{Gbps} 4$-PAM signal each.

Multilevel PAM presents a set of unique challenges in link, VCSEL and driver design. In this paper we present some of our findings about how to achieve high 4-PAM data rate transmission with VCSELs, and what are the implications of 4-PAM on the design of the VCSEL itself.

\section{DATA TRANSMISSION WITH 4-PAM AND VCSELS}

Four-level PAM can be seen as an extension of OOK, with four levels instead of two, with each level carrying two data bits. The levels can be mapped to bits using natural or Gray labeling, with bit labels arranged so that the adjacent level labels differ by one bit only. In a link with the same signal to noise ratio (SNR) 4-PAM at the same symbol rate as OOK will require $4.8 \mathrm{~dB}$ more average received optical power, compared to OOK. Consequently, it is a lot harder to close the link budget with 4-PAM, and the margins for various power penalties due to e.g. the inter-symbol interference (ISI) and relative intensity noise (RIN) are much lower. Another factor to take into account is the eye safety constraint at the $850 \mathrm{~nm}$ wavelength, which limits the transmitted optical power to around $0 \mathrm{dBm}$.

Investigation of the performance of 4-PAM under ISI, ${ }^{21-23}$ has shown that at a fixed symbol rate and channel rise time the ISI penalty for 4-PAM is twice as large as for OOK. Fig. 1 illustrates the theoretical sensitivity penalties for OOK, 4-PAM and also 8-PAM at the same symbol rate, as a function of the ratio of the data rate and the channel bandwidth. The sensitivity penalties for 8-PAM become very high, and it is very challenging to achieve high data rate transmission with 4-PAM. In the same unequalized link we have succeeded with 60 Gbps error free 4-PAM transmission, ${ }^{11}$ but only with 56 Gbps 8-PAM with bit error ratio (BER) requiring forward error correction. ${ }^{12}$

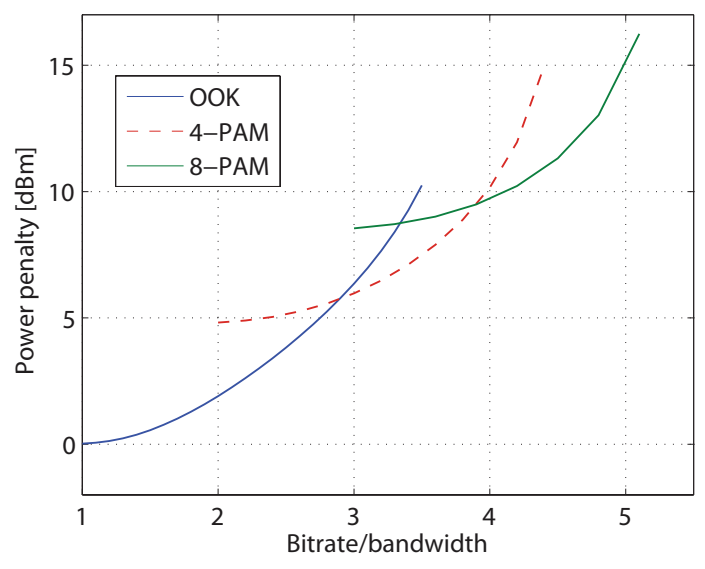

Figure 1: Sensitivity penalties due to ISI for 2-,4-, and 8-PAM, including intrinsic sensitivity difference relative to OOK. 


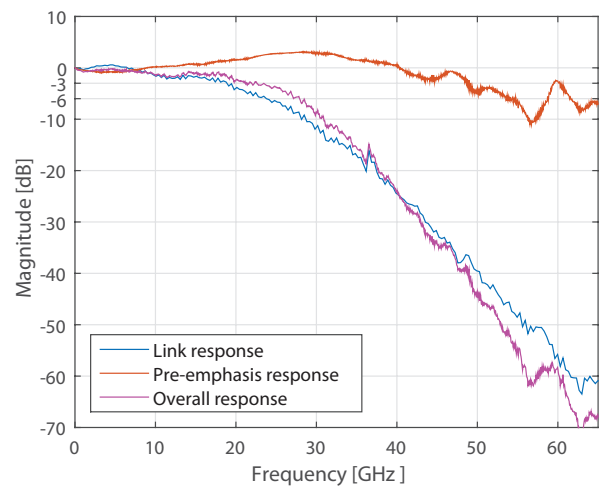

(a)

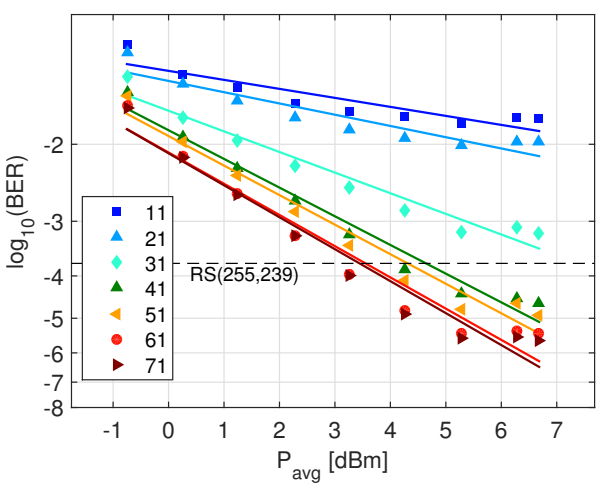

(b)

Figure 2: Frequency response of the link and the pre-emphasis(a), BER as a function of the received optical power, including the FEC input BER threshold (b).

The highest data rate which we have managed to achieve with our VCSELs to date is 94 Gbps. It was achieved using transmitter pre-emphasis, receiver equalization and forward error correction. ${ }^{13}$ Fig. 2 shows the measured frequency response of the VCSEL based link, the pre-emphasis equalizer and their combination, as well as the $\mathrm{BER}$ as a function of the received optical power. Around $3 \mathrm{dBm}$ received optical power is needed to achieve error free (post-FEC) transmission. The sensitivity could be improved, however, with better quality of the electrical signal driving the VCSEL. Nevertheless, VCSEL capable of operation at high optical output power are needed for 4-PAM operation. It may present a challenge for reduction of the transceiver energy consumption. Another important consideration is the extinction ratio. Higher extinction ratio translates to lower average optical power for the same optical modulation amplitude (OMA), but it causes a larger time skew between the levels.

The signal is affected not only by the bandwidth, but also by the shape of the frequency response of the VCSEL. A pronounced resonance peak will result in an overshoot and close the eyes of the 4-PAM signal. ${ }^{24}$ While the effect on OOK would be mainly an increase of the jitter, in case of 4-PAM it will severely degrade the signal, to the point where no data transmission will possible. Moreover, equalization of a channel with a peaky frequency response is difficult, and requires longer filters to accurately resolve the peak in the frequency domain.

The shape of the frequency response of a VCSEL is affected by the photon lifetime. A reduced photon lifetime leads to an increase of the slope efficiency, increasing the optical modulation amplitude, but reducing the photon density and damping of the modulation response. ${ }^{25,26}$ The effect of the damping and the VCSEL frequency response on the 4-PAM signal quality is illustrated in Fig. 3

Another important parameter for multilevel data transmission is the relative intensity noise (RIN). The

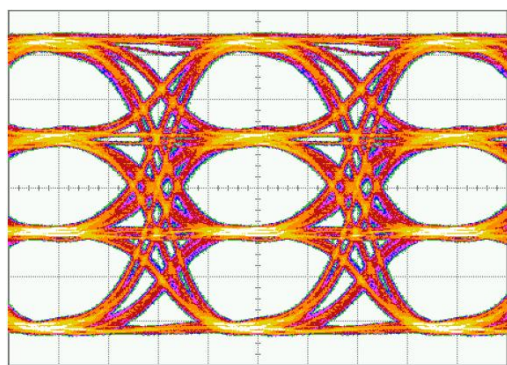

(a)

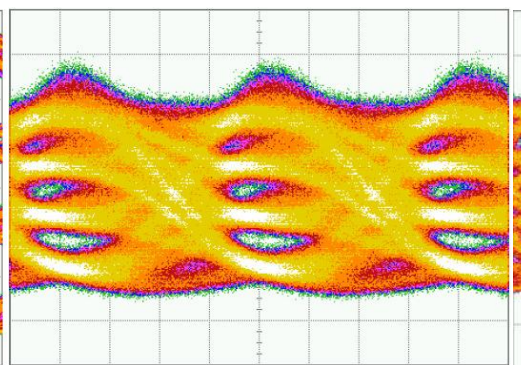

(b)

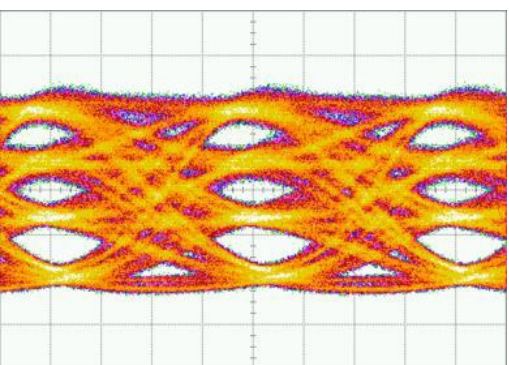

(c)

Figure 3: Eye diagrams of: the electrical 50 Gbps 4-PAM signal driving a VCSEL(a), the output of a VCSEL with photon lifetime of 3 ps (b) and the output of a VCSEL with photon lifetime of 6 ps (c). 


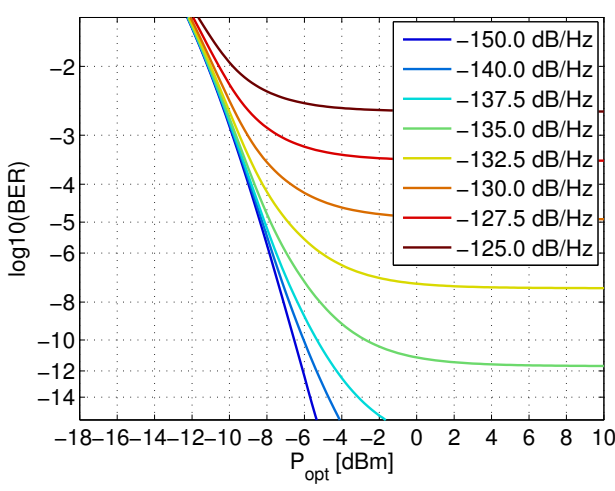

(a)

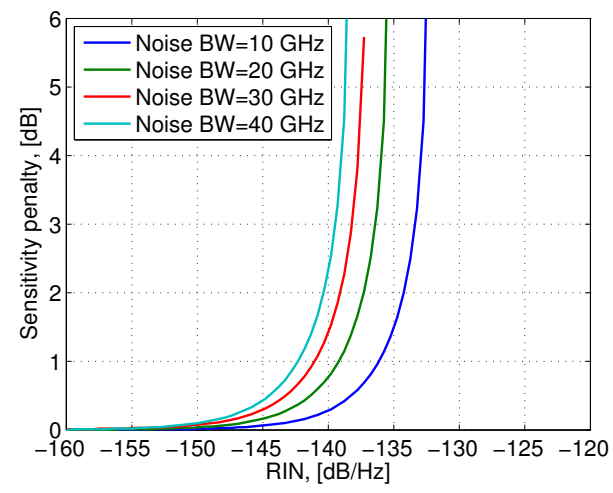

(b)

Figure 4: Theoretical BER for 4-PAM in $20 \mathrm{GHz}$ noise bandwidth with RIN between $-150 \mathrm{~dB} / \mathrm{Hz}$ and $-125 \mathrm{dBHz}(\mathrm{a})$, penalties for 4-PAM as a function RIN for noise bandwidth of 10, 20, 30 and $40 \mathrm{GHz}(\mathrm{b})$.

penalty due to RIN can be calculated from the theoretical BER expressions provided in 21,22. The main effect of RIN is an error floor, because RIN is power dependent. Fig. 4a illustrates this for theoretical BER of 4-PAM in a link with $20 \mathrm{GHz}$ noise bandwidth, typical receiver responsivity of $0.4 \mathrm{~A} / \mathrm{W}$ and varying RIN levels, assuming ISI free operation. Fig $4 \mathrm{~b}$ illustrates theoretical sensitivity penalties for 4-PAM in links with noise bandwidths of $10,20,30$ and $40 \mathrm{GHz}$ as a function of RIN. These results should be treated as upper bounds on maximum allowed RIN, because in practice the presence of other penalties means that higher received optical power levels will be necessary, and consequently RIN will be more pronounced. An experimental measurement of the power penalties due to RIN was shown in 27.

\section{VCSEL ENERGY CONSUMPTION AND MULTILEVEL MODULATION}

The next generation of links with multi-level modulation will require more transmitted OMA to close the link budgets. Therefore, it is relevant to look at the energy consumption per bit in a VCSEL in relation to the required output OMA. Previous reports of record low energy per bit in $850 \mathrm{~nm}$ VCSELs have focused mainly on VCSELs with small aperture diameters. ${ }^{2,28-30}$ This is a natural consequence of the fact that VCSELs with small apertures have low threshold currents and higher resonance bandwidths at a given bias current. This leads to a comparatively large modulation bandwidth at low bias currents, which is naturally highly desired. On the other hand, the small aperture VCSELs tend to have low maximum power output and high impedance.

We have compared energy consumption per bit for four VCSELs of the same design (implying the same differential gain and photon lifetime) but with oxide apertures of 6, 8, 10 and $12 \mu \mathrm{m}$. The detailed results are presented in 31. We have demonstrated, that at a constant extinction ratio the energy to data ratio (EDR) in high-speed VCSELs is depended on the required OMA. An example of experimentally measured EDR at an

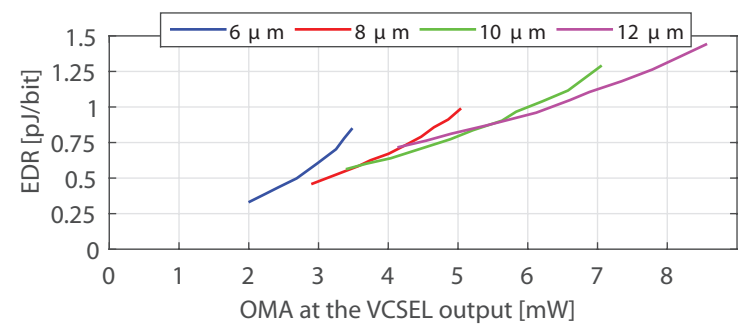

(a)

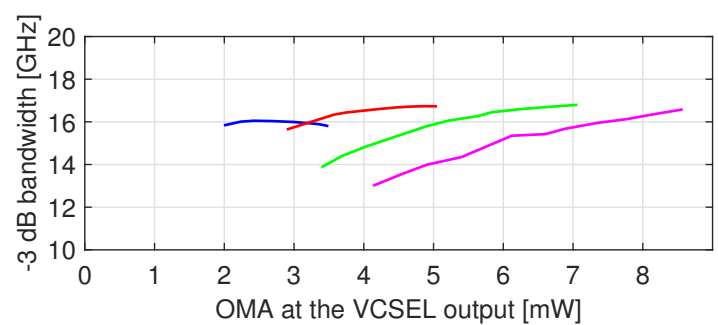

(b)

Figure 5: Energy to data ratio (EDR) as a function of the OMA for VCSELs with $12 \mu \mathrm{m}$ oxide aperture diameters(a) and the corresponding $-3 \mathrm{~dB}$ modulation bandwidth at a $6 \mathrm{~dB}$ extinction ratio (b). 
extinction ratio of $6 \mathrm{~dB}$ is shown in Fig. 5a. The oxide aperture size affects primarily the modulation bandwidth, as illustrated in Fig. 5b. When the extinction ratio is kept constant, VCSELs with smaller aperture diameters can achieve higher modulation bandwidths at lower OMA and bias current. On the other hand, the decrease in the oxide aperture diameter causes an increase of the VCSEL impedance. The two effects counteract each other, and the EDR becomes primarily a function of the OMA.

\section{DRIVER DESIGN FOR HIGH-SPEED MULTILEVEL VCSEL OPERATION}

There are various semiconductor technologies which may be used for implementations of PAM-4 drivers at 100 Gbps and beyond, such as $28 \mathrm{~nm}$ CMOS, ${ }^{32} 0.18 \mu \mathrm{m}$ SiGe BiCMOS, ${ }^{16} 0.7 \mu \mathrm{m} \mathrm{InP} \mathrm{DHBT},{ }^{33}$ and $0.5 \mu \mathrm{m} \mathrm{InP}$ HBT. ${ }^{34}$ Therefore, the driver performance is not likely to be the limiting factor for the maximum achievable optical transmission data rate. It is rather the bandwidths of the VCSEL and the photoreceiver that define the limit.

Taking advantage of the $0.25 \mu \mathrm{m} \mathrm{InP} \mathrm{technology,} \mathrm{we} \mathrm{have} \mathrm{designed} \mathrm{an} \mathrm{energy} \mathrm{efficient} \mathrm{multilevel} \mathrm{PAM} \mathrm{(2-,}$ 4-, 8-PAM) driver, hybrid-integrated with an in-house fabricated $850 \mathrm{~nm}$ VCSEL. The driver supports 100 Gbps at an energy consumption lower than $2 \mathrm{pJ} /$ bit. Due to a limited optical power budget, the performance of the PAM transmitter is verified with PAM-4 modulation in a short optical link using a commercial photoreceiver. Error-free $\left(\mathrm{BER}<10^{-12}\right)$ PAM-4 transmission at $56 \mathrm{Gbps}$ is demonstrated. This transmitter with integrated driver outperforms previous high-speed PAM-4 VCSEL transmitters in both operational data rate and energy

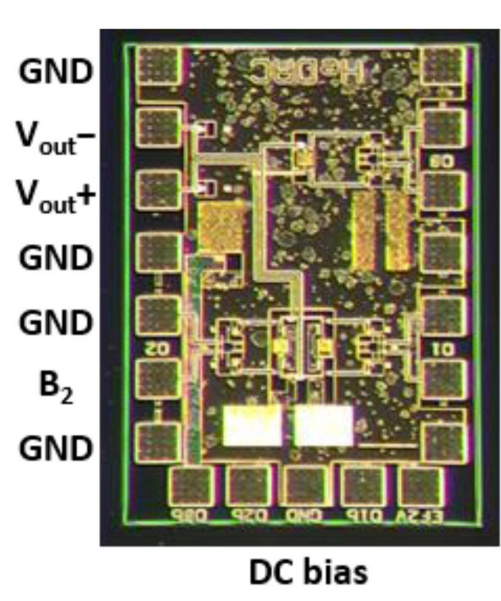

(a)

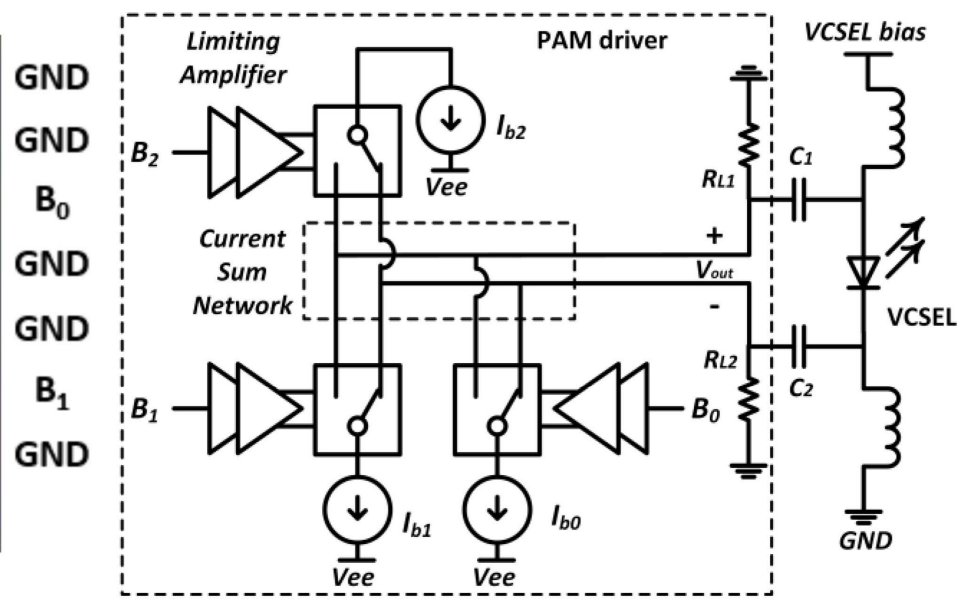

(b)

Figure 6: The fabricated InP VCSEL driver (a) and its topology (b).

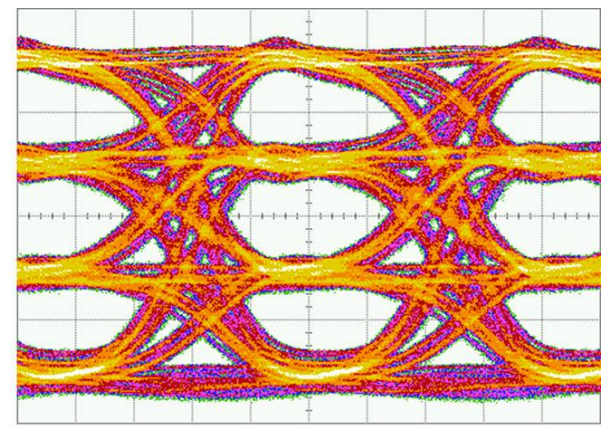

(a)

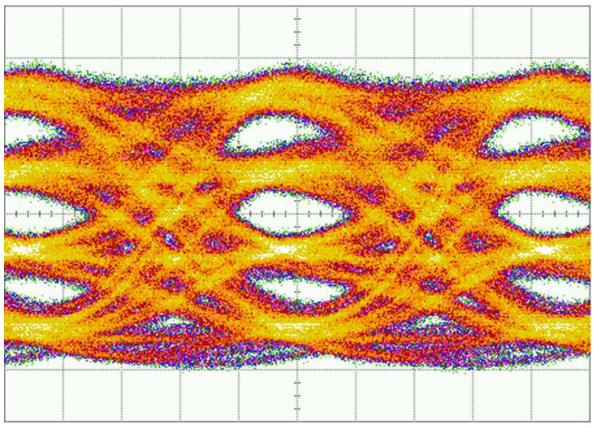

(b)

Figure 7: Eeye diagrams of the electrical 56 Gbps 4-PAM at the driver output (a) and optical 56 Gbps at the integrated transmitter output(b). 


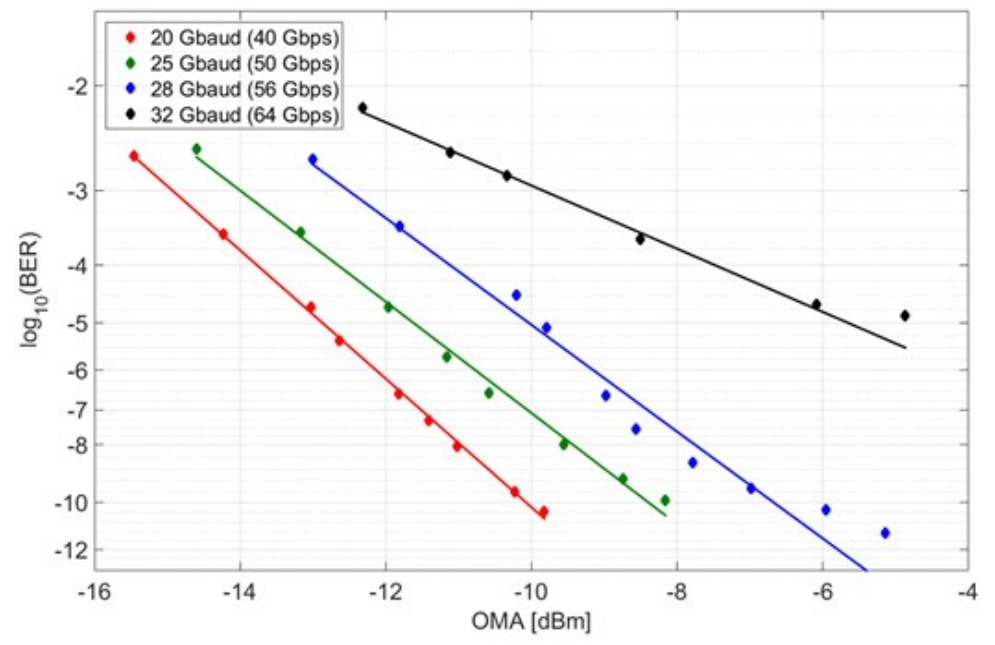

Figure 8: Measured BER in back-to-back configuration with 4-PAM and a transmitter built with an in-house designed fabricated laser and in-house designed InP driver.

efficiency. The detailed results are presented in 35. The fabricated driver circuit of size $0.68 \mathrm{~mm}$ by $1.08 \mathrm{~mm}$ is shown in Fig. 6a. The multilevel PAM driver is designed as a 3-bit digital to analog converter. It can generate up to 8-PAM signals. A functional block diagram of the driver topology is shown in Fig. 6b. The driver has three input bits $\left(\mathrm{B}_{0}\right.$ to $\left.\mathrm{B}_{2}\right)$, each input passing through a limiting amplifier, followed by a data-controlled switch connected to a tunable current source. The switches control the current flow from three current sources $\left(\mathrm{I}_{\mathrm{b} 0}\right.$ to $\mathrm{I}_{\mathrm{b} 2}$ ) to the current sum network. In this design, all three current sources can be adjusted independently using analog voltages and the driver input bits can be coupled using different weights for multilevel waveform generation. The amplitude at each output level is tunable. The limiting amplifiers have single-ended inputs and all other blocks are differential. The VCSEL can be driven differentially by connecting the driver differential outputs to the cathode and anode of the VCSEL. Alternatively, the VCSEL can be driven single-ended by terminating one of the differential outputs of the driver. A 56 Gbps 4-PAM electrical signal at the output of the driver is shown in Fig. 7a. The corresponding optical signal is shown in Fig. 7b. The BER results achieved in a back-to-back test of a transmitter are shown in Fig. 8. It is noteworthy, that error free transmission with 4-PAM is achieved at 56 Gbps at a received power level of $-5 \mathrm{dBm}$.

\section{SUMMARY}

We have demonstrated high data rate transmission using VCSELs and multilevel modulation, using both in-house VCSELs and driver amplifiers. Multilevel modulation presents however a set of unique challenges for VCSELs. No only the $-3 \mathrm{~dB}$ bandwidth but also flatness of the frequency response become important. The amplitude dependent phase shift of the VCSEL output is also challenge in transceiver design. Sensitivity penalty due to multilevel modulation means that the link budgets shrink, and therefore it is necessary to maintain output power levels close to eye safety margins, as well as high extinction ratios, which again negatively affect the linearity. Multilevel modulation formats, such as PAM are also sensitive to RIN. Fortunately, reduced RIN and improved flatness of the frequency response can be achieved together, because they are dependent on the photon lifetime.

\subsection{Acknowledgments}

We would like to thank for the financial support by the Swedish Foundation for Strategic Research (SSF) and by the Knut and Alice Wallenberg Foundation (KAW). We would also like to thank Dr Petter Westbergh for fabrication of the VCSELs used in the experiments. 


\section{REFERENCES}

[1] Haglund, E., Westbergh, P., Gustavsson, J. S., Haglund, E. P., Larsson, A., Geen, M., and Joel, A., "30 GHz bandwidth $850 \mathrm{~nm}$ VCSEL with sub-100 fJ/bit energy dissipation at 25-50 Gbit/s," Electron. Lett. 51(14), 1096-1098 (2015).

[2] Moser, P., Lott, J. A., Wolf, P., Larisch, G., Li, H., Ledentsov, N. N., and Bimberg, D., "Impact of the aperture diameter on the energy efficiency of oxide-confined $850 \mathrm{~nm}$ high speed VCSELs," Proc. SPIE 8639, 86390V-86390V-8 (Mar. 2013).

[3] Westbergh, P., Haglund, E. P., Haglund, E., Safaisini, R., Gustavsson, J. S., and Larsson, A., "High-speed $850 \mathrm{~nm}$ VCSELs operating error free up to 57 Gbit/s," Electron. Lett. 49(16), 1021-1023 (2013).

[4] Kuchta, D. M., Rylyakov, A. V., Doany, F. E., Schow, C. L., Proesel, J. E., Baks, C. W., Westbergh, P., Gustavsson, J. S., and Larsson, A., "A 71 Gb/s NRZ modulated $850 \mathrm{~nm}$ VCSEL-based optical link," IEEE Photon. Technol. Lett. 27(6), 577-580 (2015).

[5] Cole, C., "Beyond 100G client optics," IEEE Commun. Mag. 50(2), s58-s66 (2012).

[6] Lu, I. C., Wei, C. C., Chen, H. Y., Chen, K. Z., Huang, C. H., Chi, K. L., Shi, J. W., Lai, F. I., Hsieh, D. H., Kuo, H. C., Lin, W., Chiu, S. W., and Chen, J., "Very high bit-rate distance product using high-power single-mode 850-nm VCSEL with discrete multitone modulation formats through OM4 multimode fiber," IEEE J. Sel. Topics Quantum Electron. 21(6), 444-452 (2015).

[7] Ling, W. A., Lyubomirsky, I., Rodes, R., Daghighian, H. M., and Kocot, C., "Single-channel 50G and 100G discrete multitone transmission with 25G vcsel technology," J. Lightw. Technol. 33(4), 761-767 (2015).

[8] "IEEE standard for Ethernet." available online http://standards.ieee.org/findstds/standard/802. 3-2015.html accessed 2016-12-5.

[9] Zuo, T., Zhang, L., Zhou, E., Liu, G. N., and Xu, X., "112-Gb/s duobinary 4-PAM transmission over 200-m multi-mode fibre," in [Proc. ECOC], paper 0730 (Sept. 2015).

[10] Zuo, T., Zhang, L., Zhou, J., Zhang, Q., Zhou, E., and Liu, G. N., "Single Lane 150-Gb/s, 100-Gb/s and 70-Gb/s 4-PAM Transmission over 100-m, 300-m and 500-m MMF Using 25-G Class 850nm VCSEL," Proc. ECOC , 974-976 (Sept. 2016).

[11] Szczerba, K., Westbergh, P., Karlsson, M., Andrekson, P. A., and Larsson, A., "60 Gbits error-free 4-PAM operation with $850 \mathrm{~nm}$ VCSEL," Electron. Lett. 49(15), 953-955 (2013).

[12] Szczerba, K., Westbergh, P., Karlsson, M., Andrekson, P. A., and Larsson, A., "70 Gbps 4-PAM and 56 Gbps 8-PAM using an $850 \mathrm{~nm}$ VCSEL," J. Lightw. Technol. 33(7), 1395-1401 (2015).

[13] Szczerba, K., Lengyel, T., Karlsson, M., Andrekson, P. A., and Larsson, A., "94-Gb/s 4-PAM using an 850$\mathrm{nm}$ VCSEL, pre-emphasis, and receiver equalization," IEEE Photonics Technology Letters 28(22), 2519-2521 (2016).

[14] Lengyel, T., Szczerba, K., Karlsson, M., Larsson, A., and Andrekson, P. A., "Demonstration of a 71.8 Gbps 4-PAM $850 \mathrm{~nm}$ VCSEL-based link with a pre-emphasizing passive filter," in [Proc. ECOC], (2016).

[15] Karinou, F., Stojanovic, N., Prodaniuc, C., Qiang, Z., and Dippon, T., "112 Gb/s PAM-4 Optical Signal Transmission over 100-m OM4 Multimode Fiber for High-Capacity Data-Center Interconnects," Proc. ECOC , 124-126 (Sept. 2016).

[16] Lee, J., Shahramian, S., Kaneda, N., Baeyens, Y., Sinsky, J., Buhl, L., Weiner, J., Koc, U. V., Konczykowska, A., Dupuy, J. Y., Jorge, F., Aroca, R., Pfau, T., and Chen, Y. K., "Demonstration of 112-Gbit/s optical transmission using 56GBaud PAM-4 driver and clock-and-data recovery ICs," in [Proc. ECOC], paper 0604 (Sept 2015).

[17] Kanazawa, S., Yamazaki, H., Nakanishi, Y., Fujisawa, T., Takahata, K., Ueda, Y., Kobayashi, W., Muramoto, Y., Ishii, H., and Sanjoh, H., "Transmission of 214-Gbit/s 4-PAM signal using an ultra-broadband lumped-electrode EADFB laser module," in [Proc. OFC], paper Th5B.3 (2016).

[18] Castro, J. M., Pimpinella, R., Kose, B., Huang, Y., Lane, B., Szczerba, K., Westbergh, P., Lengyel, T., Gustavsson, J. S., Larsson, A., and Andrekson, P. A., "48.7-Gb/s 4-PAM Transmission Over $200 \mathrm{~m}$ of High Bandwidth MMF Using an 850-nm VCSEL," IEEE Photon. Technol. Lett. 27(17), 1799-1801 (2015).

[19] Castro, J., Pimpinella, R., Kose, B., Huang, Y., Lane, B., Szczerba, K., Westbergh, P., Lengyel, T., Gustavsson, J., Larsson, A., and Andrekson, P., "Investigation of $60 \mathrm{~Gb} / \mathrm{s}$ 4-PAM using an $850 \mathrm{~nm}$ VCSEL and multimode fiber," J. Lightw. Technol. 34(16) (2016). 
[20] Motaghian, R. and Kocot, C., "104 Gbps PAM4 Transmission over OM3 and OM4 Fibers using 850 and $880 \mathrm{~nm}$ VCSELs," in [Proc. CLEO], paper SW4F.8 (2016).

[21] Szczerba, K., Westbergh, P., Karout, J., Gustavsson, J. S., Haglund, Å., Karlsson, M., Andrekson, P. A., Agrell, E., and Larsson, A., "4-PAM for high-speed short-range optical communications," IEEE/OSA J. Opt. Commun. Netw 4(11), 885-894 (2012).

[22] Szczerba, K., Westbergh, P., Agrell, E., Karlsson, M., Andrekson, P. A., and Larsson, A., "Comparison of intersymbol interference power penalties for OOK and 4-PAM in short-range optical links," J. Lightw. Tehnol. 31(22), 3525-3534 (2013).

[23] Szczerba, K., Karlsson, M., Andrekson, P. A., and Larsson, A., "Intersymbol interference penalties for OOK and 4-PAM in short-range optical communications," in [Proc. OFC], (March 2013).

[24] Lengyel, T., Haglund, E. P., Gustavsson, J. S., Szczerba, K., Larsson, A., Karlsson, M., and Andrekson, P. A., "Impact of damping on 50 Gbps 4-PAM modulation of 25G class VCSELs," in [Accepted to OFC], (2017).

[25] Westbergh, P., Gustavsson, J. S., Kögel, B., Haglund, Å., and Larsson, A., "Impact of photon lifetime on high-speed VCSEL performance," IEEE J. Sel. Topics Quantum Electron. 17(6), 1603-1613 (2011).

[26] Haglund, E. P., Westbergh, P., Gustavsson, J. S., and Larsson, A., "Impact of damping on high-speed large signal VCSEL dynamics," J. Lightw. Technol. 33(4), 795-801 (2015).

[27] Pavan, S. K., Lavrencik, J., and Ralph, S. E., "Experimental demonstration of 51.56 gbit/s pam-4 at $905 \mathrm{~nm}$ and impact of level dependent rin," in [Proc. ECOC], paper P.7.23 (Sept. 2014).

[28] Wolf, P., Moser, P., Larisch, G., Li, H., Lott, J. A., and Bimberg, D., "Energy efficient 40 Gbit/s transmission with $850 \mathrm{~nm}$ VCSELs at $108 \mathrm{fJ} /$ bit dissipated heat," Electron. Lett. 49(10), 666-667 (2013).

[29] Moser, P., Lott, J. A., Wolf, P., Larisch, G., Li, H., Ledentsov, N. N., and Bimberg, D., "56 fJ dissipated energy per bit of oxide-confined $850 \mathrm{~nm}$ VCSELs operating at 25 Gbit/s," Electron. Lett. 48(20), 1292-1294 (2012).

[30] Moser, P., Lott, J. A., Wolf, P., Larisch, G., Payusov, A., Ledentsov, N. N., and Bimberg, D., "Energyefficient oxide-confined 850-nm VCSELs for long-distance multimode fiber optical interconnects," IEEE J. Sel. Topics Quantum Electron. 19(2), 7900406-7900406 (2013).

[31] Szczerba, K., Westbergh, P., Gustavsson, J. S., Karlsson, M., Andrekson, P. A., and Larsson, A., "Energy efficiency of vcsels in the context of short-range optical links," IEEE Photonics Technology Letters 27(16), 1749-1752 (2015).

[32] Huang, H., Heilmeyer, J., Grzing, M., Berroth, M., Leibrich, J., and Rosenkranz, W., "An 8-bit 100-gs/s distributed dac in 28-nm cmos for optical communications," IEEE Trans. Microw. Theory Tech., 63(4), 1211-1218 (2015).

[33] Konczykowska, A., Jorge, F., Dupuy, J. Y., Riet, M., Nodjiadjim, V., Aubry, H., and Adamiecki, A., "84 GBd (168 Gbit/s) PAM-4 3.7 Vpp power DAC in InP DHBT for short reach and long haul optical networks," Electron. Lett. 51(20), 1591-1593 (2015).

[34] Nagatani, M., Wakita, H., Nosaka, H., Kurishima, K., Ida, M., Sano, A., and Miyamoto, Y., "75 GBd InP-HBT MUX-DAC module for high-symbol-rate optical transmission," Electron. Lett. 51(9), 710-712 (2015).

[35] Chen, J., He, Z. S., Lengyel, T., Szczerba, K., Westbergh, P., Gustavsson, J. S., Zirath, H., and Larsson, A., "An energy efficient 56 Gbps PAM-4 VCSEL transmitter enabled by a 100 Gbps driver in 0.25 um InP DHBT technology," J. Lightw. Technol. 34(21), 4954-4964 (2016). 